\title{
Decision-Making processes for effective problem solving to potentiate organisation sustainability
}

\author{
Maria José Sousa \\ Jorge Miguel Martins \\ Miguel Sousa
}

\begin{abstract}
The purposes of this article are to analyse the decision-making processes for practical problem solving, and to understand the ways employees make decisions, based on the knowledge they have from previous problems solutions. To achieve these objectives, the following research questions were used to frame this study: Do employees have access to knowledge and tools to help them in their decision process on how to solve a particular problem? What kind of decision-making strategies for problem-solving situations can be implemented to make the organisation sustainable? One large-sized multinational organisation in Portugal was selected for this case study research. Fifteen employees were interviewed to provide insight into the research questions. The research findings support the conclusion that depending on the complexity of the problem, the employee needs to decide if he has the knowledge and the tools to achieve a solution to solve the problem. The use and share of employees' knowledge to make the decisions is a significant factor to solve problems and strengthen performance.
\end{abstract}

Keywords: Decision Making, Problem Solving, knowledge, sustainable organisations 


\section{Introduction}

To overcome the problem-solving situation and facilitate decision-making processes (Dhami et al. 2015; Curseu \& Schruijer 2012) organisations create problem-solving routines. According to Johnson (1995), problem-solving involves three phases: preparation (understanding the problem); production (developing different alternative solutions) and judgment (the decision needed for selecting a solution). Argyris and Schön (1996) suggest a fourth phase: review and reflective assessment of both outcomes and processes.

Even with that kind of routines implemented to help the organisation make decisions and respond to problem situations, knowledge integration is also conditioned by its complexity (Ederer et al. 2016) and because factors are depending on the source/receiver of knowledge that affects the practical use and integration of knowledge.

These new quality criteria have the goal to improve the transfer of problem-solving knowledge with the application of previously learned knowledge to solving a new problem (Mayer \& Wittrock 1996). Moreover, Nonaka et al. (2000) assume that knowledge can be an enabler or a disabler of problem-solving.

In this context, it is essential to understand the strategies that organisations use in their decisions making process, both for employees and managers. This study analyses the ways employees use their knowledge to make operational decisions to solve the emergent issues, with the goal of understanding and contributing to a more efficient process.

To achieve that aim, it is necessary to gather data about employee's perceptions about the process, as they seek ways to facilitate the decision-making (Fischer 2015; Fox \& Poldrack 2014; Frederick 2005) based on individual knowledge and that leads to useful problem-solving routines.

To find out how organisations empower their employees in the decision-making process to solve problems (Gettinger, Kiesling, Stummer, \& Vetschera 2013), this study intends to answer the following research questions:

1. Do employees have access to knowledge and tools to help them in their decision process on how to solve a particular problem?

2. What kind of decision-making strategies for problem-solving situations can be implemented to make the organisation sustainable?

This topic introduced the study, presenting an overview of the background and problem statement, outlined the purpose of the investigation, stated the research question and a brief theoretical perspective. The review of the literature will focus on knowledge management, decision-making processes, and problem-solving routines.

The methodological framework used is a qualitative case study, followed by topics which discuss the findings of the study, provides the implications for theory and practice and recommends directions for future research. 


\section{Literature Review}

\subsection{Decision-making Processes}

Decision-making is portrayed by bounded rationality; a close and critical link exists between the nature and limitations of human decision and the structure and activity of the organisation. Cyert and March (1963), pointed out that in an established organisation, a scope for decision-making is limited by prior decisions, either explicit or implicit, as well as being restrained by moral commitments to individuals and departments. These authors developed a model of the firm that behaves as an entity, similar to the pattern of the goal-directed, economising, and learning individual. This decision-making coalition model focuses on cost, as well as on the decisions of the firm. Like Simon (1945), they emphasise both a theory of search and a theory of choice. Nevertheless, it is crucial to assume that past decisions can influence new decisions (Greiff et al. 2015).

For the scope of this paper, strategic decisions are those fundamental decisions which are "important, regarding actions taken, the resources committed, or the precedents set" (Mintzberg et al 1976). They are the decisions made by the managers and employees of an organisation that can affect its performance. Selznick (1957) differentiates the strategic decision (critical) from the routine decision. Key decisions are the responsibility of the managers and fall into four categories (tasks). The first task involves the definition of the institutional mission and role. The second is to make and shape "character-defining," the institutional embodiment of purpose, which includes building policy into the structure or deciding upon the means to achieve the ends desired. The third task is to preserve the institutional integrity. Drucker (2002) emphasises that strategic decisions are multi-dimensional decisions, which will have an impact on the future of the enterprise. From this perspective, the great difficulty lies in finding the right question, not the right answer (Ackoff 1970). The fundamental role of top managers is seen as shaping organisational objectives and strategy, with tactics intervening to define organisations' relations with their resource environments. Thus, strategy and strategic decisions act as an important driver of businesses' performance outcomes.

In contrast to strategic decisions, operational decisions are internally focused and absorb much of the agency's time and effort, as they are the decisions made about the organisation's daily functioning. Examples of these types of decisions would be the allocation of resources, scheduling tasks, and monitoring performance. Ackoff (1970) defines planning as anticipatory decisionmaking, which is comprised of two planning components: strategic and tactical. Strategic planning decisions are those which are broad in scope, have long-term effects, and are related to organisational goals. Tactical decisions are concerned with selecting the most efficient means to achieve the targets set in the strategic plan. Ackoff stresses that both are needed to maximise the organisation's progress and that planning at the corporate level is more strategic than it is at any other level in the hierarchy.

The main point is that these decisions directly affect the nature and the success of the firm. Other key points are that they include choices about new products or markets (Ackoff, 1970), as well as decisions about organisation design and the adoption of new technologies. Such decisions are typically novel and occupy the thinking of senior management. However, they can be significantly influenced by people lower down in the organisation (Bower, 1970). Bower's conclusions are aligned with the study of Crozier (1964), who discusses the relative power and the basis of the authority of four groups within the monopoly: production workers, maintenance workers, lower supervisors, and the management team. Although the strength of the management team is severely limited by the rationalisation of the work process, the maintenance workers have a good deal of power in such a system because the machine breakdown is "the last source of uncertainty remaining in a completely routinised organisational system." (Crozier 1964). The 
relationship among the participants demonstrates how a person with technically the lowest power could, in part, control the initiation of action by others.

Braybrooke and Lindblom (1963) reinforce the complexity of decision-making processes in organisations, and they explain that the integration of parts of the information is a very convoluted process and therefore limited by the capacities to understand the relationship of all the parts. It is not, therefore, a techno-scientific accomplishment but a result of practical procedures. The approach to decision-making process assumes, aforementioned, several limitations. First, the employee has limited problem-solving capacities. Second, the inadequacy of information and third, the cost of the analysis process. Additionally, the evaluation method of the results of the decision-making process, the balance of observed facts and results. Nonetheless, the openness of the process and the diverse forms and contexts in which problems arise (Braybrooke and Lindblom 1963).

\subsection{Problem Solving Techniques}

Billett (2001) distinguish between routine and non-routine problems: Routine problems involving situations that have been experienced before: A) Simple, repetitive and well-understood situations, which are handled in a tacit mode, with very little conscious thought. The pure nature of these cases allows for easy explication. B) Routine situations within a different context, when workers face problems that are similar but are not exact repetitions of previous experiences. When routine problems become more involved, the capability to address critical situations depends on the ability of each one, to recognise and diagnose the problem quickly.

Non-routine problems need workers' knowledge to solve novel problems that may represent their most valuable contribution: A) Solving novel problems need workers' ability to define the problem and to work collaboratively with other employees from different sections to find a solution. B) Emergent problems can be described as workers proactively identifying problems to explore or process improvement or new work situations. C) Solving problems outside of expertise: these are problems that are unique and outside of their existing domains of experience and know-how.

\subsection{Sustainable Organizations and inherent Psychology of Sustainability}

Since the United Nations published the World Commission on Environment and Development (WCED, 1987), remarks regarding sustainability became vital in any managerial discussion (Dyllick \& Hockerts 2002). While several industries continuously operate and vision their future, as activists towards a positive ecologic impact or, by reducing the consumption of scarce resources, often, it is from within their internal approach that the highest dignity of sustainability occurs.

H.R. (Human Resources) Managers acknowledged the importance of attracting and retaining talent, maintaining employee's health and safety and, or fostering CSR (Corporate Social Responsibility) strategies. Furthermore, Pfeffer (2010) describes the concern for human sustainability which balances interests and needs between employees and their companies'. However, particularly the generation $\mathrm{Y}$ wants to pursue a career in a corporate environment which is strongly influenced and focus on sustainability, green management, and social responsibility. Therefore, H.R. managers have a critical role in designing these desirable settings, if aligned with the shareholders' interests.

Regarding Sustainability's etymological meaning and origin, it refers to sustain with ability. This article focusses on the capacity of employees to foster organisational sustainability. Di Fabio and Gori (2016) described this same capacity as the core of individual intrapreneurial resources, supported by an explanation that employees are often faced with severe constraints of resources, changes and transitions, therefore, the positive relational management (Di Fabio 2016b) to foster 
organisational well-being or civility. Aforementioned, there are a set of instruments that should be made available to employees such as, knowledge and tools, to support the overhead reflection issues. Furthermore, for the agents to have a methodology to base their decision process.

In a business context, companies have been pointed as a significant key-driver to achieve organisational development (Bansal 2005). Leal Filho (2000) argues that a shared meaning of sustainability is a strategy for corporate sustainability. Therefore, there must be a prepredisposition from the internal stakeholders to successfully achieve those as mentioned earlier.

Di Fabio (2017) concluded that challenges are a sort of opportunity for organisations to develop its well-being in the unpredictable environment characteristic of the 21 st century. For this reason, understanding the underlying psychology of sustainability becomes a powerful knowledge for organisations to promote a healthier workplace environment and to deliver competitiveness for its operations.

\subsection{Problem Solving to Potentiate Organizations Sustainability}

Retaining highly qualified employees is of vital importance to the long-term viability of businesses. Workers become familiar with the company's culture. Each business will have different approaches to deal with chronic psychological stress at work. For employees to make wiser decisions, enterprises must provide them with the resources and instruments to achieve that goal. Therefore, it is a role of the SHRM (Strategic Human Resources Manager) to define a sustainable corporate approach. Moreover, the meaningfulness of the organisation vision needs to be acknowledged by its human capital as their own: Di Fabio (2016a), describes this relationship in several forms, whether as a work-life project, an organisational project, an inter-organisational project or as a group project. The same author emphasises and infers that projects sustainability is directly tied to the feeling of coherence, direction, purpose, significance and belonging of its member. Kurt Lewis defined that Behaviour as a function given by the individual characteristics of a person with the environment offered by organisations. Moreover, the fundamental attribution error is of greatest importance, both in individual and organisational understanding: in others, generally, we overestimate the role of personal factors and underestimate the role of situational factors (i.e. the personality of an individual and their life circumstances, correspondently).

However, while pursuing organisational development or team management, it is critical to understand that people differ in their motivational drivers whilst, this paradigm might be oversimplified in the following major elements: (1) extrinsic motivation - doing the job for a tangible reward, to gain intangible social benefits or to directly avoid a punishment (i.e. a competitive wage/reward, to not be dismissed from a job or social popularity, respectively); (2) intrinsic motivation - the act of doing the job successfully, mastering a technique or procedure, or pure enjoyment per se, solely brings a feeling self-reward and therefore, internal gratification which is transformed into a motivational driver; (3) transcendent/altruist - the motive of collaborating in a task ultimately relies on the philanthropic purpose or the positive impact that it may cause on other people's lives. Notwithstanding, the motivation psychology adverts for the extrinsic incentive bias which explains how often people misunderstand and misinterpret the importance of extrinsic factors for others and inappropriately uses it as a bargaining tool, leading to a poor motivation capability. Moreover, the Vroom Expectancy Theory explained the motivation as a result of:

\section{Motivation $=$ Expectancy $*$ Instrumentality $*$ Valence}

This motivational theory may be interpreted as follows in which (1) expectancy is understood as the probability that people's effort leads to performance, i.e. "If I put a higher effort in this task, will I perform as expected from me?"; (2) instrumentality, as the belief that performance leads to a reward, i.e. "If I perform as expected from me, will I be rewarded?"; (3) valence, which is the 
inherent individual value assigned to the offered reward by the organisation, i.e. How do I value the reward that would be given to me?

According to the notion of Sustainable HRM, for employees be able to express themselves with confidence and to trust the process, there must be a practice of Human-Resources Mindfulness. This concept aims to enhance organisational awareness through anticipation and coping with great practices. Table 1 synthesises the highest principles of OM (Organisational Mindfulness). To potentiate corporate sustainability through problem-solving, there must be a regular exchange of perspectives and direct participant of knowledge employees. Furthermore, it is decisive to design expectations, work-related interests, and mostly experience-based knowledge through storytelling. OM approach aims to allow those internal stakeholders to express their voice without fear of retaliation when they face a moment of critical decision-making.

Table 1. Organisational Mindfulness (OM)

\begin{tabular}{|c|c|c|}
\hline Principles of OM & Outputs & Literature \\
\hline $\begin{array}{l}\text { Reluctance to simplify } \\
\text { interpretations }\end{array}$ & $\begin{array}{l}\text { [1] Promote scepticism to identify and to reduce blind } \\
\text { spots - mitigate unforeseen events by collaborative } \\
\text { mindset; } \\
\text { [2] Organize an exchange of different point of views } \\
\text { among internal stakeholders based on an innovation- } \\
\text { driven; } \\
\text { [3] Exchange of knowledge through experience-based. }\end{array}$ & $\begin{array}{l}\text { (Weick \& } \\
\text { Sutcliffe, } \\
\text { Managing the } \\
\text { unexpected, 2001) } \\
\text { (Weick \& } \\
\text { Sutcliffe 2007) }\end{array}$ \\
\hline $\begin{array}{l}\text { Sensitivity and } \\
\text { attentiveness to local } \\
\text { operations }\end{array}$ & $\begin{array}{l}\text { [1] Involve employees and their tacit knowledge; } \\
\text { [2] Anticipate or detect harmful health-related side } \\
\text { effects of workflows or unexpected events in project } \\
\text { work; } \\
\text { [3] Adapt from work practices and routines to an } \\
\text { awareness-model where unexpected events are part of } \\
\text { the process. }\end{array}$ & $\begin{array}{l}\text { (Weick \& } \\
\text { Sutcliffe 2007) } \\
\text { (Becke 2013) } \\
\text { (Siegrist 1996) }\end{array}$ \\
\hline $\begin{array}{l}\text { Commitment to } \\
\text { resilience }\end{array}$ & $\begin{array}{l}\text { [1] Entails the ability to "bounce back from errors and } \\
\text { handle surprises at the moment"; } \\
\text { [2] Intervention practices that alter problematic frame } \\
\text { conditions of knowledge work to facilitate employees' } \\
\text { regeneration of health resources; } \\
\text { [3] Rebalancing reciprocity between management and } \\
\text { workers, especially concerning reorganisation } \\
\text { processes. }\end{array}$ & $\begin{array}{l}\text { (Vogus \& } \\
\text { Welbourne 2003) } \\
\text { (Becke 2013) }\end{array}$ \\
\hline
\end{tabular}




\begin{tabular}{|c|c|c|}
\hline $\begin{array}{l}\text { Underspecification of } \\
\text { the structure }\end{array}$ & $\begin{array}{l}\text { [1] "Fluid decision-making" which enables } \\
\text { organisations to turn decision structures upside down } \\
\text { during periods of emergency or severe crisis, thereby } \\
\text { utilising local expert knowledge as an organisational } \\
\text { resource for containing and coping with hazards; } \\
\text { [2] Deferred work autonomy employees can draw on to } \\
\text { cope effectively with unexpected events in work } \\
\text { processes. }\end{array}$ & $\begin{array}{l}\text { (Vogus \& } \\
\text { Welbourne 2003) } \\
\text { (Weick \& } \\
\text { Sutcliffe 2007) }\end{array}$ \\
\hline $\begin{array}{l}\text { Preoccupation with } \\
\text { failure }\end{array}$ & $\begin{array}{l}\text { [1] Errors and near misses are conceived as sources of } \\
\text { organisational learning; } \\
\text { [2] Potential failures or adverse side effects of HR } \\
\text { strategies and practices can be attributed to a structural } \\
\text { imbalance between economic, social and ecological } \\
\text { dimensions; } \\
\text { [3] Requires an infrastructure that combines a vigilant } \\
\text { awareness of unintended side effects and failures; } \\
\text { [4] Practices with a structure that facilitates } \\
\text { (organisational) learning from failure. }\end{array}$ & $\begin{array}{l}\text { (Weick \& } \\
\text { Sutcliffe 2007) }\end{array}$ \\
\hline
\end{tabular}

Organisational routines can be conceptualised as "repetitive, recognisable patterns of interdependent actions, carried out by multiple actors (Feldman \& Pentland 2003). Routines are identified by the duality of structure and agency (Giddens 1984): there are, therefore, repeated social interactions that must be maintained, reproduced and altered by the human agency. In this way routines can be sustainable according to the definition explained previously.

Routines involve humans' capacity to interpret, to modify, to re-enact and to adjust habits to unpredictable work processes and contexts (Levinthal \& Rerup 2006). There must be, therefore, a reflective learning curve within an organisation. The reflection in matter refers to each actor, where are influenced by their knowledge and previous experiences. Based on this practice of inquiry the past, employees will be able to pursue sustainable outcomes from their decisions better. According to the table 1, the Organisational Mindfulness provides a set of tools or HRM system that provides employees access to knowledge and tools to help them in their decision process to solve unexpected or specific problems (Fischer et al 2017).

According to (Jordan, Messner, \& Becker 2009) in the mindful HR-infrastructure, there are two basic variants of organisational routines:

1. Promote collective mindfulness through the practice of reflections in ongoing, work-related operations and interactions. Aforementioned is, for instance, to start and follow-up regularly with the assigned team, to update, adjust and solve. The author recommends that this structure should be informal and most flexible (scrum-meetings). This methodology allows internal stakeholders if there is a purpose, pre-disposition, and awareness, to pursue sustainable development, to continuously self-monitor and self-reflect over difficulties of the project itself or from its peers. Therefore, for this goal, organisations must sensitise their employees for health-related issues, without a formal committee for the purpose. It shall develop solutions to cope with stressors collectively in ongoing work processes, mostly by the flexibilization and redistribution of project tasks, offer social support and approach project managers with confidence and trust that the employee's well-being is of great significance for the organisation sustainability. 
2. Reflection-on-action takes place outside work operations (Jordan, Messner, \& Becker 2009) such as training's, reviews of completed projects or steering committees. The importance of this is to create awareness on the top-managers for arising health-related problems within smaller segments of the business. Communications between this two parties will necessarily overview the decision-making process of employees and its consequences. By making use of this awareness towards peers', will enable companies to be more efficient approaching their H. R. and consequently, creates a meaningful engagement of employees with their roles within the organisation.

\section{Research Methodology}

The methodological approach was qualitative, and it was applied the method of cases or intensive analysis. Furthermore, the data was gathered through interviews with employees.

\subsection{Research Findings}

The context of the organisation helps to understand the perceptions of the workers according to the procedures used to problem-solving situations and the decision-making process.

In respect to the problem-solving methodology we acknowledge that it is framed by production methodology used by the organisation and it has established rules that define the autonomy and the complexity of the problems that can be solved by each level of workers:

"We have a good system of decision-making in problems solving situations, and it is part of the new methodology of work." (Middle Managers)

"Workers have autonomy to take decisions to solve less complex problems, and problems and solutions are registered in a database that can be consulted when a problem occurs, facilitating the use of knowledge." (Department Managers)

Workers have an essential role in problem-solving situations. Their knowledge is the critical factor to identify the problem and the possible solutions.

Production Managers who work directly with the workers have identified workers with two different attitudes:

"a) Workers that don't show any concern about the problems. b) Workers that try to help in an individual base and when they cannot solve the problem, they communicate it to the shift Manager." (Production Managers)

The organisation uses temporary workers when necessary and when the contract of some of these workers is near its end, they assume a hostile attitude and do not show any concern for the quality, the achievement of production goals or the product quality. However, it seems that most workers have an active link to the organisation showing involvement and participating in the decisionmaking process at their level of responsibility.

During the research process it was identified the following decision-making strategies to make the organisation sustainable: 


\section{Strategy 1 - be open-minded and autonomous}

Most of the knowledge in organisations is dynamic because it is concentrated on workers, but some of that knowledge is static (documental information, for example). It is essential that the dynamic knowledge can be stored in repositories which over a period will become a substantial source of relevant information and expertise.

"Each workplace has one level of autonomy associated, in respect to decision-making and problem resolution." (Production Managers)

"If I have a simple problem in my machine, normally I know how to fix it. It is only when the problem seems to be very complex tht I consult my shift Manger" (Operators)

Knowledge can be a criterion for autonomy and decision-making. The more knowledgeable workers are, the more potential they have and the more autonomous they can be, unlike other workers that are less knowledgeable. When the worker's range of knowledge is more comprehensive, his contribution is more significant, and he is in a position to make some technical decision.

"It is possible to seek a description of the problem's resolution, and access a set of quality tools: analysis, diagnosis, information and research." (Middle Managers)

During the workday, workers face several problems, and they solve most of them in an unconsciously (in a tacit way), automatically and in a few seconds. Other situations require more time, effort, teamwork and collaboration. Situations can vary widely: some are well known and require routine, even automated knowledge, while others are more complex and require extensive abstract knowledge.

"When there is a problem, we have some technical procedures that we need to follow. If it is a simple problem that the Operator knows how to solve, he can make the decision without consultation of the manager. If he cannot discover a solution, he then informs the Team Manager, and together they try to find a solution. If it is a very complex problem, a team with several Operators and Technicians is created to analyse the problem. The Operator that finds the problem also participates in this team that meets one time per week to decide the more efficient corrective solutions." (Department Managers)

It is important to point out the alignment of perception in every hierarchical position according to decision-making and problem resolution procedures. During Technicians interviews, they described an identical procedure or routine when a problem occurs to Department Managers and Middle Managers. They said that when a problem emerges:

"Depending on the complexity of the workstation, the Operator decides if he has the knowledge and the tools to solve the problem by him or if he needs help from the shift Manager. If the problem is too complex, he does not have the autonomy to decide the solution to the problem, and then he informs the Shift Manager that evaluates the type of problem, like if it is a quality problem or if it assumes some other form." (Technicians)

Operators also have a similar perception of problem resolution:

"If it is a problem in a machine, the evaluation is made by me. I have the autonomy to make the first evaluation. If the problem is very complex, we have an internal system that initiates with an intervention order send to maintenance, and it is also communicated to the shift Manager."

"If it is a quality problem, all the production stops, and we quickly analyse the problem, trying to identify the phase where it has initiated. Sometimes the problem started in the previous shift." 
"In the Welding section the procedures are the same: we analyse the problem, and if we can, we solve it. The remaining problems are registered in proper documentation." (Operators)

Using (Piaget, J. 1996) distinction of problem types as either routine or non-routine, (Billett 2001) identified routine problems like the ones "requiring individuals to expend little conscious or effortful thinking". Routine problems are addressed through a process called assimilation, that is, the ability to act gained through repeated practice, without conscious thought. Solving routine problems reinforces and refines existing knowledge.

"For instance, if it is a quality problem, we have some procedures that we need to follow according to the Quality Manual, and the problems need to be registered as well as their specific solution. The people involved in the problem and the solution are also identified so that if another problem like that occurs in another area of the plant, all employees have access to the problems and solutions database." (Department Managers)

Non-routine, or novel problems, require "extensive conscious thinking" (Billett 2001) and extended knowledge through accommodation (Piaget, J., 1996). The learning occurs when one encounters a new task or challenge. Solving novel problems enables workers to identify and close gaps in knowledge and learn new models, clues and cues on how to proceed'.

"Solving new problems gathers the involved people in the discussion of the solution. They discuss the problem, identify it and implement several actions according to the problem resolution." (Middle Managers)

The use of routines in creating and using knowledge in decision-making processes to problemsolving began with the problem-finding phase, and then the problem is analysed by the Operator and/or the shift Manager. If they cannot solve the problem, they consult the quality database where they store all problems and solutions. If the problem is too complicated, they created a team to solve it, and when they find the solution, they implement it and register the problem and its solution in the database.

\section{Strategy 2 - focus on the needs of the business}

Workers are more prepared to solve technical problems then organisational ones:

"Some problems are mere anomalies that employees can identify, and they have an easy solution, especially when we are dealing with technical problems, and not with organisational ones (for these they do not have the necessary knowledge). This has been an everyday battle, with systematic procedures thought to make all the employees involved in the decision-making process." (Production Managers)

Workers are always looking for new ways to improve their practices and routines. Middle Managers focused on a particular issue and determined to implement a more efficient methodology of problem-solving.

"There is going to be implemented a more rigorous, standard and detailed methodology, not only in the production lines but also in the other sections of the organisation. Production System is going to organise what already is a good practice, making it even more efficient." (Middle Managers)

"Problem resolution is the priority; correcting problems is something that we think about constantly and whenever the machines are working. Our priority is keeping a continuous production process." (Middle Managers)

"We are already well equipped to facilitate problem-solving situations, and the plant organisation is an important factor, but we are creating standards that will help to solve problems more quickly." (Middle Managers) 
According to Johnson (1955), problem-solving involves three phases: preparation (understanding the problem); production (developing different alternative solutions) and judgment (selecting a solution). Argyris and Schön (1996) suggest a fourth phase: review and reflective assessment of both outcomes and processes.

Even if it is essential to have tools, procedures and routines to help the organisation respond to problem situations or challenges, this kind of factors can sometimes be a barrier to new knowledge development and even to knowledge use.

The problem-solving approach creates a high level of interaction and the closeness and the trust among workers is the key to the degree of tacit knowledge shared. Most problem situations are solved unconsciously, automatically and in a few seconds. Other situations require more time, effort, teamwork, collaboration and extensive abstract knowledge.

\section{Strategy 3 - think about what makes the organisation different from others}

The routines created for decision-making in the problem-solving process began with the problemfinding phase; then the problem is analysed by the Operator and/or the shift Manager. If they cannot solve the problem, they consult the quality database where they store all problems and solutions. If the problem is too complicated, they created a team to solve it, and when they find the solution, they implement it and register the problem and the corresponding solution in the database.

The organisation has several routines to create and share knowledge and Production System imposes a constant creation of new knowledge, especially regarding the organisational innovation process.

The innovation process is a critical factor because of the importance of implementing new ways of production and new organisational processes to accomplish higher efficiency. Involving workers in this process requires the use of management tools such as communication and the promotion of workers' involvement and participation. The organisation uses several mechanisms to promote knowledge share and develop new ideas. It is important to point out the suggestions system (mainly used to make production improvements), the workshops on innovations and new products, and the knowledge networks (especially the informal ones).

Looking for another perspective, we can say that this organisation is a learning space at a technical and organisational level. One of the most useful tools to create and disseminate knowledge is through workshops with people from different sections or people from just only one section.

Costumers and external specialist often participate in the workshops and help the discussion and the creation of new knowledge that helps implement new practices, tools or technology. There is a connection between sharing knowledge and achieving the business goals or solving practical problems.

\section{Conclusions}

This research contributes to understanding the decision-making process in problem-solving situations. The decision process depends on the knowledge, ability, and level of responsibility for the employees. Thus, on complex problems, it is hard to determine which decision is best. According to Ackoff (1970), the most critical aspect is the process of planning, a process focused on timing, sequence, and dynamics. Billet (2001) proposes a typology for decisions.

In light of the theory and also the empirical results it is possible to state that this organisation has a routine of problem-solving implemented that includes several phases: it began with the problemfinding phase; then the problem is analysed by the Operator and / or the Manager. If they cannot 
solve the problem, they consult the quality database where they store all challenges and solutions. If the problem is too complicated, they created a team to address it, and when they find the solution, they implement it and register the problem and the corresponding solution in the database. Each worker has the autonomy to make decisions to solve problems associated with their level of responsibility and depending on the complexity of the problem.

Three strategies of problem-solving with the goal to make the organisation more sustainable were identified the following strategic approaches:(1) - be open-minded and autonomous; (2) - focus on the needs of the business; and (3) - think about what makes the organisation different from others. They can contribute to the construction of a model of decision-making in problem-solving situations and be a support, helping to identify solutions and creating new organisational and technical practices and processes.

\section{References}

Ackoff R. L. (1970). A concept of corporate planning. New York: Wiley.

Argyris C., \& Schön D. (1996). Organisational learning II: Theory, method and practice, Reading, Mass. Addison Wesley.

Bansal P. (2005). Evolving sustainably. Longitudinal Study Corp Sustain Dev, 26(3), 197-218.

Becke G. (2013). A concept for social sustainability at organizational level. In G. Becke, Mindful change in times of permanent reorganization: Organizational Institutional Perspectives. Heidelberg: Springer.

Billett S. (2001). Learning throughout working life: Interdependencies at work. Studies in Continuing Education, 19-35.

Bock et al. (2005). Behavioural intention formation knowledge sharing: examining roles of extrinsic motivators, social-psychological forces, and organisational climate. MIS Quarterly, 29, 87-111.

Bower J. L. (1970). Managing the Resource Allocation Process. Irwin: Homewood.

Braybrooke D., \& Lindblom C. E. (1963). A strategy of Decision. Free Press.

Crozier M. (1964). The Bureaucratic Phenomenon. London: Tavistock.

Curseu P., \& Schruijer S. (2012). Decision styles and rationality: an analysis of the predictive validity of the general decision-making style inventory. Educ Psychol Meas, 72(6), 10531062.

Cyert R. M., \& March J. G. (1963). A Behavior Theory of the Firm. Englewood Cliffs: Prentice Hall.

Dhami M. K., Mandel D. R., Mellers B. A., Tetlock P. E. (2015). Improving intelligence analysis with decision science. Perspect. Psychol. Sci. 10, 753-757.

Di Fabio A. (2016a). Constructing and Managing Personal Project, Career Project, Life Project: The Challenge of Sustainability. Invited lecture at the seminar organized by the Faculty of Health Sciences, Hokkaido University, Sapporo, Japan.

Di Fabio A. (2016b). Positive Relational Management for healthy organizations: psychometric properties of a new scale for prevention for workers. Front. Psychol. 7:1523. doi: 10.3389/fpsyg.2016.01523 
Di Fabio A. (2017). Promoting Sustainable Development and Well-Being in a Culturally Diverse World. Keynote at the First international cross-cultural conference "Healthier societies fostering healthy organizations: A cross-cultural perspective" organized by the Department of Education and Psychology, University of Florence, May 26-27, 2017, Florence. Co-presidents F. Cheung, J.-M. Peirò, D. H. Saklofske, and F. van de Vijver.

Di Fabio A., and Gori A. (2016). Developing a new instrument for assessing acceptance of Change. Front. Psychol. 7:802. doi: 10.3389/fpsyg.2016.00802

Drucker P. (2002). Managing in the Next Society. New York: Truman Talley.

Dyllick T., \& Hockerts K. (2002). Beyond the business case for corporate sustainability. Bus Strategy Environ, 11, 130-141.

Ederer P., Patt A., Greiff S. (2016). Complex problem-solving skills and innovativeness evidence from occupational testing and regional data. Eur. J. Educ. 51, 244-256.

Feldman M. S., \& Pentland B. T. (2003). Reconceptualizing organizational routines as a source of flexibility and change. Adm Sci $Q, 48,94-118$.

Fischer A., Greiff S., Funke J. (2017). "The history of complex problem solving," in The Nature of Problem Solving: Using Research to Inspire 21st Century Learning, eds Csapó B., Funke J., editors. (Paris: OECD Publishing; ), 107-121.

Fischer A., Holt D. V., Funke J. (2015). Promoting the growing field of dynamic decision making. J. Dynamic Decis. Mak. 1, 1-3.

Fox C. R., \& Poldrack,R. A. (2014). Prospect Theory and the brain. In Handbook of Neuroeconomics. New York: Elsevier.

Frederick S. (2005). Cognitive reflection and decision making. Journal of Economic Perspectives, 19(4), 25-42.

Gettinger J., Kiesling E., Stummer C., \& Vetschera R. (2013). A comparison of representation for discrete multi-criteria decision problems. Decision Support Syst, 54, 976-985.

Giddens A. (1984). The constitution of society. Berkeley: The University of California Press.

Greiff S., Fischer A., Stadler M., Wüstenberg S. (2015). Assessing complex problem-solving skills with multiple complex systems. Think. Reason. 2, 356-382.

Johnson D. M. (1955). The Psychology of Thought and Judgement. New York: Harper.

Jordan S., Messner M., \& Becker A. (2009). Reflection and mindfulness in organizations: rationales and possibilities for integration. Managerial Learning, 40(4), 465-473.

Leal Filho W. (2000). Dealing with misconceptions on the concept of sustainability. Int $J$ Sustainability in High Education, 1(1), 9-19.

Levinthal D., \& Rerup C. (2006). Crossing an apparent charm: Bridging mindful and less-mindful perspectives on organizational learning. Organ Sci, 17(4), 502-513.

Mayer R. E., \& Wittrock M. C. (1996). Problem-solving transfer. In D. C. Berliner, \& R. C. Calfee, Handbook of educational psychology (pp. 47-62). New York: Macmillan.

Mintzberg H. et al. (1976). The structure of "unstructured" decision process. Administrative Science Quarterly, 21(2), 246-275.

Nonaka I. et al. (2000). SECI, Ba and leadership: a unified model of dynamic knowledge creation. Long Range Planning, 33, 5-34. 
Pfeffer, J. (2010). Building sustainable organizations: the human factor. Acad Manage Perspect, $24,34-45$.

Piaget, J. (1967). Autobiographie. Cahiers Vilfredo Pareto, 4(10), 129-159

Selznick P. (1957). Leadership in Administration. New York: Harper and Row.

Siegrist J. (1996). Adverse health effect on high-effort/low-reward conditions. Journal of Occupational Health Psychology, 1(1), 27-41.

Simon H. A. (1945). Administrative Behavior. New York: Free Press.

Vogus T., \& Welbourne T. M. (2003). Structuring for high reliability: HR practices and mindful processes in reliability-seeking organizations. Journal of Organizational Behaviour, 24(4), 877-903.

WCED. (1987). Our common future. Oxford: Oxford University Press.

Weick K. E., \& Sutcliffe K. M. (2001). Managing the unexpected (1st Edition ed.). San Francisco: Jessey-Bass.

Weick K. E., \& Sutcliffe K. M. (2007). Managing the unexpected (2nd Edition ed.). San Francisco: Wiley.

\section{About the authors}

Maria José Sousa (Ph.D. in Management) is a University Professor and a research fellow at ISCTE/Instituto Universitário de Lisboa. Her research interests are political and information science, entrepreneurship and innovation, and management issues. She has co-authored over 70 articles and book chapters and published in several scientific journals. She has organised international conferences and is guest-editor of three Special Issues.

mjdcsousa@gmail.com

J. Miguel Martins is a Chartered Economist and Chartered Manager in Iceland. His professional background includes financial consulting in Portugal, banking in the United Kingdom, and research, auditing and operations consulting in Iceland.

Miguel Sousa is a student at the University of Essex with specialization on Economics/Business Studies, and Information Systems. He is pParticularly interested in Business and Marketing, namely Digital Marketing, Innovation, and Entrepreneurship. 